International Review of Research in Open and Distributed Learning Volume 16, Number 3

June -2015

\title{
Exploring Students' Intention to Use LINE for Academic Purposes Based on Technology Acceptance Model
}

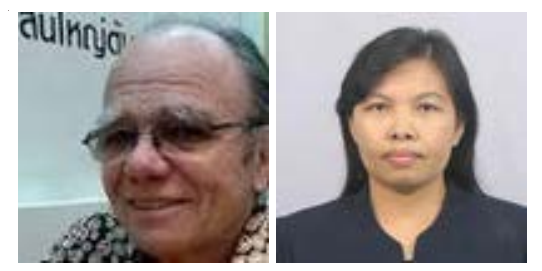

Willard Van De Bogart and Saovapa Wichadee Bangkok University, Thailand

\begin{abstract}
The LINE application is often conceived as purely social space; however, the authors of this paper wanted to determine if it could be used for academic purposes. In this study, we examined how undergraduate students accepted LINE in terms of using it for classroom-related activities (e.g., submit homework, follow up course information queries, download materials) and explored the factors that might affect their intention to use it. Data were collected from 144 undergraduate students enrolled in an English course that utilized some activities based on LINE app using a questionnaire developed from TAM. Data were analyzed to see if relationships existed among factors when LINE was used to organize classroom experiences. The findings revealed that perceived usefulness and attitude toward usage had positive relationships with intention to use while perceived ease of use was positively related to perceived usefulness. In contrast with TAM assertions, this study did not find any relationship between perceived ease of use and attitude toward usage. Also, the number of social networking sites that students are using had no relationship with intention to use. The study also suggested some kinds of LINE-based learning activities preferred by students, which would be proposed for future courses. This study revealed several useful implications that TAM can be employed as a useful theoretical framework to predict and understand users' intention to use new technologies in education.
\end{abstract}

Keywords: LINE; technology acceptance; language teaching; perception 


\section{Introduction}

The development of on-line talk or chat has become increasingly pervasive within emerging social networks proliferating in every country and every educational level of students. The issue for educational technologists as well as teachers who are teaching ESL utilizing on-line chat apps is whether these applications can support and encourage students to learn English (Gonzalez, 2003). What is also significant in these studies on the effectiveness of using chat to increase conversation skills is that when students' styles of learning are better understood, the chances of their conversation skills becoming better are increased (Hsieh, 2011; Hsu, 2007). Nowadays, information and communication technologies (ICTs) have a great impact on the process of students' participation in a course (Greenhow \& Robelia, 2009). Apart from formal technical systems like syllabi, course management systems (e.g., Moodle, Blackboard), or university-owned email distribution lists that universities use to support courses, informal systems such as the Facebook and LINE applications seem to play a significant role in the teaching and learning processes. Although these social networking sites are usually used for social interaction, they can also be looked at as potential communication channels where students collaborate for academic purposes. They enable learners to discuss course content and cooperate with each other easily (Palloff \& Pratt, 2007; Gabarre \& Gabarre, 2013).

Online chat applications such as LINE can greatly facilitate informal communication around classroom activities since it can be easily accessed. LINE (http://line.naver.jp/en/) is a new communication application which allows users to make voice calls and send messages whenever and wherever they are. LINE has more than 330 million users worldwide and is used in over 230 countries (Horwitz, 2012). LINE has been ranked no. 1 in the free app category in 40 countries including J apan, Taiwan, Hong Kong, Thailand, Singapore, and more. With the availability of LINE app and 3G networks, instructors can use LINE to contact students, while students can also use it to contact their instructor and peers. Engaging more with peers and teachers increases their learning efficacy. In addition, LINE can increase students' critical thinking by building knowledge through what is called "social constructivism." It is the immediacy afforded by chat apps which gives students an immediate connection with the teacher as well as other students. For instance, if students are required to give a reply to a question, they can give responses that are faster and more to the point than if students had to sit down and write the answer out on paper. We can see a great deal of collaboration and an increase in the number of students who offer responses.

The generation gap which normally exists between students and teachers can be bridged by using stickers and emoticons attached to text messages when using LINE. The LINE chat app offers the user many expressive characters that can be attached to a standalone message to convey a feeling or even represent an attitude. According to Stapa and Chaari (2012), some of the emoticons are used to strengthen the message, while others represent certain tone of voice such as surprise, anger, disappointment, sadness and astonishment. By utilizing emoticons or stickers like facial expressions mixed in with text messages, students are finding new ways to explore their own 
feelings without being threatened as they might feel in a real face-to-face situation. The small stickers provided by the LINE chat app show moods and reactions to events; when selected they provide a way to express feelings or even offer advice to a problem or a reaction to something that has happened to their friends in an everyday life situation. One of the benefits for a teacher to use an emoticon or sticker is that it relates to the students' world and allows the teacher to participate in the expressive world emulated by these emoticons and stickers. LINE is constantly updating their characters providing more choices for personal self-expression. By offering stickers that have many different character types to choose from, a student can develop their personalities (Wee, 2013) and express their attitudes just by choosing a sticker character, which in many ways is similar to creating a personal avatar in 3D virtual space. Both emoticons and characters define new ways LINE users can explore their own behavioral traits without relying only on words or use them as a substitute for how they would respond to a real life situation. Teachers who interact with their students use these emoticons and stickers as a way to break down generation gaps and at the same time explore new ways of responding to specific situations within the students' world.

\section{LINE Usage in an English Course at a Private University}

We have recently included the LINE chat app as an integral part of expressing ideas within a classroom setting where both students and teacher could interact. Every class created a dedicated group of students who would interact with one another as guided and structured by the teacher. This social interaction within a classroom group community provided the teacher with an opportunity to analyze on-line interaction and LINE chat conversations. A useful model to help understand LINE discourse analysis has been developed to analyze LINE talk interaction (Mazur, 2004). The types of conversations which have been developed in response to teacher assignments were the driving reasons for conducting an in-depth student questionnaire to determine what the attitudes towards using LINE chat in the classroom were. The results of this survey indicate that the way in which a question is structured for one student using the LINE chat app has a direct bearing on the response from another student. Variations in how students respond to questions have also been analyzed for the depth and completeness of the students' answers. Synchronous learning with direct responses coming from one student to another student allow for an active conversation that is related to an assignment (McBrien et al., 2009). Although the finding shows a positive attitude students had toward incorporating LINE into classroom activities, more analysis is still required to determine the long term effectiveness in building learners' conversation skills and a channel for communicating with them. Therefore, the present study aimed at investigating Thai undergraduate students' LINE usage for academic purposes utilizing the Technology Acceptance Model (TAM). Three factors in TAM were taken to study with the belief that they might influence the acceptance of new technology. When LINE is incorporated into the coursework, we need to ensure that LINE is user-friendly. If the technology is not easy to use, it will not be perceived as useful. The issue of ease of use cannot be excluded since it may affect students' acceptance of LINE usage for academic purposes. Attitude toward usage and perceived usefulness were the other two factors in TAM which our research focused on. Apart from this, the present study added one more factor; namely the number of social networking sites which This work is licensed under a $\underline{\text { Creative Commons Attribution } 4.0 \text { International License }}$ 
students are using. Students may have different usage behaviors of social networks. Some may heavily depend on social network sites while others may not pay much attention to them. The former seems to possess more technological skills, so they are more likely to adopt LINE for coursework. When the new technology is implemented into our course, we may encounter difficulties if we do not know how students perceive it. As such, we need to explore their perceptions and factors that have an impact on intention to use. The findings will help us have a better understanding on how these factors support or resist technology acceptance in language teaching.

The conceptual framework in this study was adapted from TAM as follows.

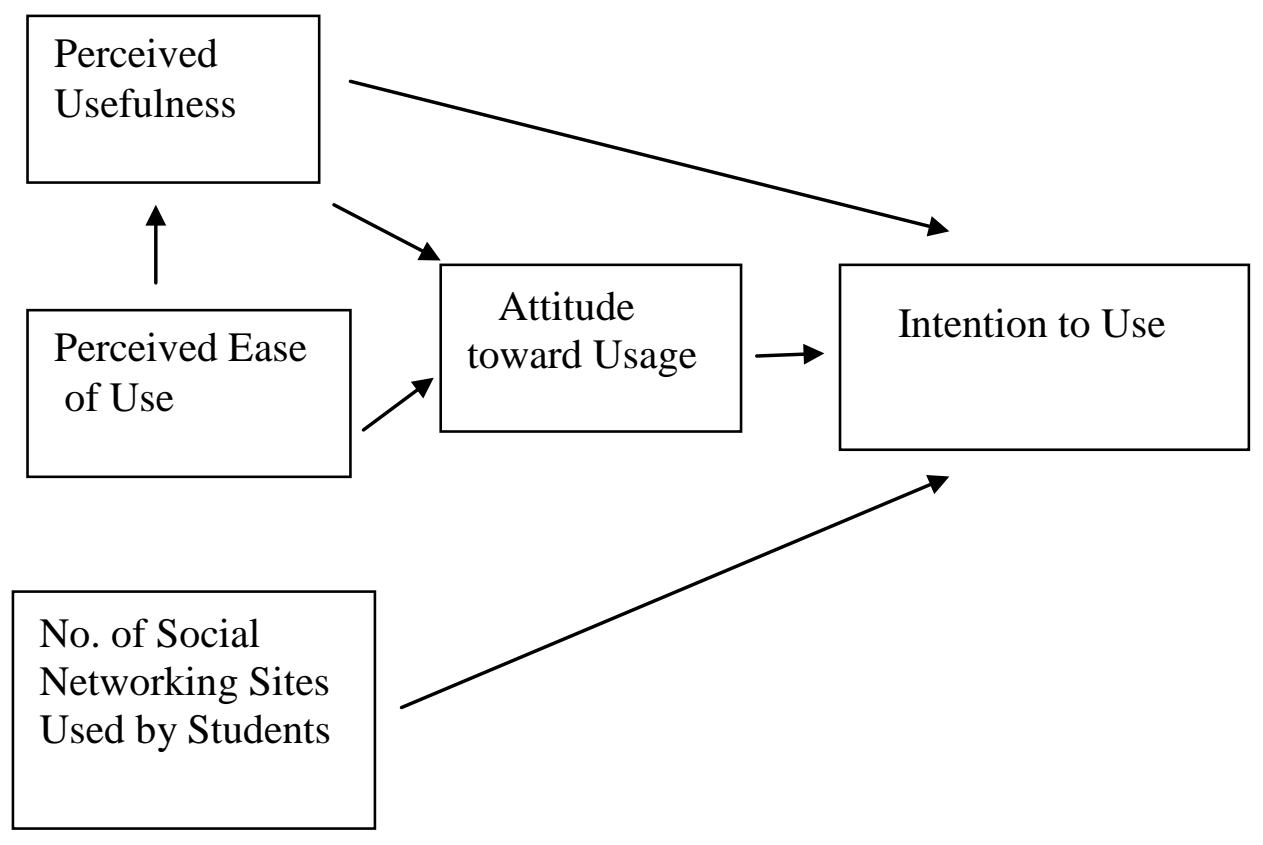

Figure 1. Technology acceptance model adapted from Davis et al (1989).

The five research questions guiding this study included:

1. What social networks are students using in their daily life, and what is the most effective tool to communicate with the teacher as perceived by them?

2. What do students report concerning attitude towards LINE usage for academic purposes, intention to use LINE, perceived ease of LINE use and perceived usefulness of LINE in their study? 
3. Are there any relationships between students' intention to use LINE, attitude towards LINE usage, perceived ease of LINE use, perceived usefulness of LINE, and the number of social networking sites they are using?

4. What LINE-based activities do students prefer to have in future English courses?

5. What are the benefits and drawbacks of LINE usage for academic purposes?

\section{Theoretical Background and Hypotheses}

\section{Technology Acceptance Model (TAM)}

To better understand the attitudes and behaviors of students using LINE in an academic study, a research model had to be found which addressed early adoption and usefulness of a new technology as well as measuring the feedback to improve users' acceptance of the technology. In as much as the LINE chat app has already gained over 330 million users worldwide, it is safe to assume that the reason for such a high early adoption of this new technology is because of its ease of use within social networking communities throughout the world. Because of the exponential growth of LINE, the TAM model was selected as it addresses the issue of immediacy of use. But we also considered the acceptance of other types of activities that LINE offers the user such as sharing audio and video clips. The Technology Acceptance Model (TAM) developed by Davis (1985) attempts to understand the relationship between the perceptions users have of a new technology before they use it. Essentially, Davis has constructed a model which analyzes the perceived usefulness of a new computer technology. By studying these perceptions of users we can better understand the acceptance of these new technologies and determine if the student can learn more effectively when using them.

To this end Davis devised three factors impacting user acceptance of a new computer technology which our research focused on. The first factor to be considered was Perceived Usefulness (PU); the second was Perceived Ease of Use (PEOU); and lastly Attitude Toward Usage (ATU) of a new system (Davis, 1989). This model has a direct relationship to the usage of LINE by students at Bangkok University. The measurements developed to analyze student use of LINE focuses on these three factors. PEOU is defined as how easy the user perceives the new technology is to use (Park, 2009a; Venkatesh \& Davis, 2000a). Perceived Usefulness (PU), however, is defined as the user's belief that the technology will improve their performance (Lee \& Lee, 2008; Venkatesh \& Davis, 2000b). Attitude Toward Usage (ATU) resulting in behavioral intention of whether to use or not use the technology is another determining factor to be explored (Nov \&Ye, 2008).

This work is licensed under a Creative Commons Attribution 4.0 International License. 
TAM has gained support for being a powerful model for predicting the early adoption of new technologies that can be used in various situations and in different contexts (Park, 2009a; Teo, 2009). TAM application within a learning context is beneficial. This model helps us to analyse the reasons for resistance toward the technology usage in the learning process and would further enable us to take efficient measures to improve user acceptance. It has been used in a variety of technologies such as e-learning, mobile phone, e-portfolio, and Facebook during the past few years. According to Davis (1989), systems are evaluated for two main purposes: 1) to predict acceptability; and 2) to diagnose the reasons resulting in lack of acceptance in order to take proper measures to improve user acceptance. So, application of TAM would allow a better understanding of why some technologies do not gain much popularity of use in education while some do. The system success can be measured from students' acceptance and usage, which results in learning more effectively. In other words, the acceptance of technology is considered a major step toward implementing and developing a successful online learning environment. On the contrary, a lack of acceptance can be used to decide whether the new technologies should be implemented in the course or not.

Many studies have been conducted to find the factors influencing the intention to use technologies using TAM. The results of these studies indicated that students' perceived ease of use had a significant influence on attitude towards usage (Shroff et al., 2011). Perceived ease of use had the strongest significant influence on perceived usefulness (Shroff et al., 2011) and attitude toward use (Park, 2009b; Chang et al., 2012). Perceived ease of use was found to indirectly impact intention to use through increased perceived usefulness (Sek et al., 2010; Lee et al., 2011). Perceived usefulness was a direct determinant of intention to use (Liu et al., 2005). Yi and Hwang (2003) found a direct and significant influence between behavioral intention and actual usage of the web-based environment in their study. Similarly, Ng, Shroff, and Lim (2013) used TAM to explain why users accept or reject information technology, and they found that attitude towards usage evidenced a direct relationship to behavioral intention to use.

\section{Research Hypotheses}

After reviewing literature, the six research hypotheses are defined as follows:

H1: Students' perceived usefulness will be positively related to their intention to use. H2: Students' attitude toward usage will be positively related to their intention to use.

H3: The number of social networking sites students are using will be positively related to their intention to use.

H4: Students' perceived ease of use will be positively related to perceived usefulness.

H5: Students' perceived ease of use will be positively related to their attitude toward usage.

H6: Students' perceived usefulness will be positively related to their attitude toward usage.

This work is licensed under a Creative Commons Attribution 4.0 International License. 


\section{Method}

\section{Participants}

The participants were students who enrolled in a bachelor's degree level course titled, English for Communication Arts Professionals, offered at a university in Thailand during the second semester in 2013. It was a 3-credit, 14-week compulsory course taken by the second year students from the School of Communication Arts. Of the 165 students who enrolled in the course, some students missed the survey distributed to them in class while some failed to complete it; therefore, a total of 144 students participated in this study.

The selection of this course was based on the following. Firstly, the course content offered opportunities to create activities using LINE; such as discussing the topic provided and giving a response to a very detailed question as to what constitutes an unethical advertisement. Secondly, this course was a pilot project; LINE was used instead of the Learning Management System to connect with students, so students needed to follow up the course contents or announcements through LINE.

\section{Research Instrument}

The instrument of this study was a questionnaire comprising four main sections. The first section contained data concerning age, gender, as well as subject taken. It also asked about Internet access on mobile phone, kinds of social networks they were using, and perceived effective tools for communicating with teachers. Section Two was based on prior studies with modifications to fit the specific context of LINE usage, developed from the TAM scales, adapted from Davis et al. (1989). This part consisted of 26 items that measured "perceived ease of use" (8 items), "perceived usefulness" (10 items), "attitude towards usage" (5 items) and "intention to use LINE" (3 items). A five-point Likert scale response format was used with the following categories: $5=$ strongly agree; 4 = agree; 3 = undecided; 2 = disagree; and $1=$ strongly disagree. The third section asked students to tick any class activities they would like to have in future English courses. They could select more than one choice. The last section provided two open-ended questions. The participants specified what they viewed as the main benefits and drawbacks of LINE usage for coursework.

The questionnaire was translated into Thai language. Since most of the items were adapted to suit the present context, the constructs in the research model could not be operationalised using standard scales from past literature. Therefore, the items in the draft questionnaire were examined and corrected by three experts in the English teaching field for clarity and accuracy using Index of Item-Objective Congruence developed by Rovinelli \& Hambleton (1977). To check how well the items tap the established objectives, the three experts evaluated each item by giving the item a rating of 1 (for clearly measuring), -1 (clearly not measuring), or 0 (degree to which it

This work is licensed under a Creative Commons Attribution 4.0 International License. 
measures the content area is unclear) for each objective. According to Brown (1996), if the value of IOC is higher than 0.5 , the item is acceptable due to its congruence between the objective and content, but if it is lower than 0.5 , the item is unacceptable because of the lack of congruence. The values of congruence index for all items in Section II were proper because they were between 0.67 and 1.00. The experts' comments and suggestions in terms of the wording and statement of each description were considered for modification of the questionnaire. To investigate the internal consistency among all items, the questionnaire was piloted with 40 university students. The reliability analysis was performed, and the inter-item reliability (Cronbach's alpha) of these items was .96, indicating a high level of internal consistency or a high level of redundancy of items within the questionnaire.

\section{Data Analysis}

Data were statistically recorded and analyzed by SPSS/ Windows program. Personal data of the participants and a survey of social networks use were calculated for frequency and percentage. Students' intention to use, perceived ease of use, perceived usefulness, attitude toward usage were analyzed quantitatively for means and standard deviations. Exploratory factor analysis was used to find out factor loadings. A reliability analysis, using Cronbach's alpha, was undertaken to test the reliability of each of the factors. The factor scores derived from exploratory factor analysis were then calculated for relationships using regression analysis to test the hypotheses. Path analysis was conducted to examine the proposed model. The class activities that students preferred to have in future courses were calculated for frequency and percentage.

\section{Research Findings}

\section{Part I: Findings of Quantitative Data}

Research Question 1: What social networks are students using in their daily life, and what is the most effective tool to communicate with the teacher as perceived by them?

Among the 144 students with complete surveys, 75\% were 16-20 years old, and 25\% were older. Of these, $53.5 \%$ were female and $46.5 \%$ were male. In this section, the theme of access is explored. Upon asking students if they have Internet access on their mobile phone, the vast majority (95.8\%) owned a mobile device that is capable of accessing the Internet. When students were asked to identify the kinds of social networks they were using, the findings revealed that LINE was chosen the most (95.8\%), followed by Facebook (91.7\%), YouTube (81.9\%), Skype (31.9\%), Twitter (26.4\%), Wiki (10.4\%), and Instagram (6.3\%). Further analysis was undertaken to find out how many social networking sites students were using. The findings revealed that $43.1 \%$ of them used three kinds of social networks, $20.1 \%$ used four kinds of social networks, $12.5 \%$ got

This work is licensed under a Creative Commons Attribution 4.0 International License. 
involved with five kinds, $10.4 \%$ used two kinds, 5.6\% used only one social network, $4.2 \%$ used six kinds, and $4.2 \%$ used seven kinds. In addition, the results indicated that LINE was the most effective tool for communicating with teachers that students perceived (76.4\%), followed by Facebook (16.7\%), e-mail (3.5\%), LMS (2.8\%), and Skype (0.7\%).

Research Question 2: What do students report concerning attitude towards LINE usage for academic purposes, intention to use LINE, perceived ease of LINE use and perceived usefulness of LINE in their study?

The descriptive statistics of the four constructs are shown in Table 1. All items were rated at high levels since they were above 3.50, and the standard deviations ranged from 0.64 and 1.07.

Table 1

Mean and Standard Deviation of Factors

\begin{tabular}{|c|c|c|c|}
\hline Factors & Item & Mean & S.D. \\
\hline \multirow{8}{*}{ Perceived Ease of Use } & 1 & 4.13 & .85 \\
\hline & 2 & 4.12 & .81 \\
\hline & 3 & 4.04 & .83 \\
\hline & 4 & 4.44 & .83 \\
\hline & 5 & 3.86 & .90 \\
\hline & 6 & 4.44 & .75 \\
\hline & 7 & 4.49 & .67 \\
\hline & 8 & 4.44 & .72 \\
\hline \multirow{10}{*}{ Perceived Usefulness } & 1 & 3.76 & .90 \\
\hline & 2 & 4.00 & .84 \\
\hline & 3 & 4.22 & .86 \\
\hline & 4 & 3.99 & .87 \\
\hline & 5 & 3.94 & .90 \\
\hline & 6 & 4.06 & .91 \\
\hline & 7 & 3.87 & .98 \\
\hline & 8 & 4.08 & .96 \\
\hline & 9 & 3.91 & 1.07 \\
\hline & 10 & 4.01 & .91 \\
\hline \multirow{5}{*}{ Attitude toward Usage } & 1 & 4.33 & .67 \\
\hline & 2 & 4.37 & .64 \\
\hline & 3 & 4.32 & .64 \\
\hline & 4 & 4.38 & .65 \\
\hline & 5 & 4.36 & .64 \\
\hline \multirow{3}{*}{ Intention to Use LINE } & 1 & 4.33 & .67 \\
\hline & 2 & 4.13 & .85 \\
\hline & 3 & 4.49 & .67 \\
\hline
\end{tabular}


For the process of exploratory factor analysis, the twenty-six statements were analyzed using principle components analysis with varimax rotation method to determine the underlying dimensions. The Kaiser-Meyer-Olkin (KMO) measure of sampling adequacy and the Bartlett's test of sphericity were used to test the fitness of the data. The result of KMO was 0.883 and the Bartlett's test of sphericity was found at the significance level of 0.000 , indicating that the use of factor analysis was appropriate. Hair, Anderson, Tatham, and Black (1998) suggested that the minimum Eigen value of 1.00 be used as cut-off, and factor loading of more than 0.50 was retained. Four dimensions were extracted from twenty-six statements. No statements were deleted as their factor loading was more than 0.50. The Cronbach's alpha ranged from 0.735 to 0.920, which surpassed the criteria for reliability acceptability (Hair et al., 2006). The four factors were "perceived ease of use", "perceived usefulness", "attitude toward usage", and "intention to use."

Table 2

Factor Analysis of the Four Constructs

\begin{tabular}{|l|l|l|l|l|}
\hline & $\begin{array}{l}\text { Factor } \\
\text { loading }\end{array}$ & $\begin{array}{l}\text { Eigen } \\
\text { value }\end{array}$ & $\begin{array}{c}\text { \% of } \\
\text { Variance }\end{array}$ & Alpha \\
\hline Factor 1: Perceived Ease of Use & & 9.042 & 34.778 & .880 \\
\hline 1. send videos or pictures to others & .694 & & & \\
\hline 2. watch videos or see pictures & .711 & & & \\
\hline 3. save videos or pictures & .680 & & & \\
\hline 4. send stickers or emoticons to others & .642 & & & \\
\hline 5. create and update personal profile & .591 & & & \\
\hline 6. telephone through LINE & .646 & & & \\
\hline 7. type and send messages & .662 & & & \\
\hline 8. create a group in LINE & .641 & & & \\
\hline Factor 2: Perceived Usefulness & & 3.985 & 15.327 & .920 \\
\hline 1. watch videos as a self-study & .621 & & & \\
\hline $\begin{array}{l}\text { 2. work together on assignments in LINE } \\
\text { group }\end{array}$ & .720 & & & \\
\hline 3. submit homework to the teacher & .710 & & & \\
\hline $\begin{array}{l}\text { 4. ask the teacher or peers to clarify the } \\
\text { unclear contents or discuss about } \\
\text { assignments }\end{array}$ & .708 & & & \\
\hline $\begin{array}{l}\text { 5. get feedback or suggestions on assignments } \\
\text { from the teacher }\end{array}$ & .754 & & & \\
\hline 6. make an appointment about study & .796 & & & \\
\hline $\begin{array}{l}\text { 7. download teaching materials from the } \\
\text { teacher }\end{array}$ & .737 & & & \\
\hline $\begin{array}{l}\text { 8. express feelings related to a study using } \\
\text { emoticons or stickers }\end{array}$ & .663 & & & \\
\hline 9. view score reports & .633 & & & \\
\hline 10. follow up the course information & .724 & & & \\
\hline Factor 3: Attitude toward Usage & & & & \\
\hline
\end{tabular}




\begin{tabular}{|l|l|l|l|l|}
\hline 1. I think LINE makes learning easier. & .901 & & & \\
\hline $\begin{array}{l}\text { 2. I have a generally favorable attitude toward } \\
\text { using LINE. }\end{array}$ & .766 & & & \\
\hline $\begin{array}{l}\text { 3. I like the idea of using LINE for academic } \\
\text { purposes. }\end{array}$ & .744 & & & \\
\hline $\begin{array}{l}\text { 4. Using LINE provided me with a lot of } \\
\text { enjoyment. }\end{array}$ & .740 & & & \\
\hline $\begin{array}{l}\text { 5. It is a good idea to use LINE for my } \\
\text { coursework. }\end{array}$ & .818 & & & \\
\hline Factor 4: Intention to Use LINE & & 1.579 & 6.072 & .735 \\
\hline 1. I intend to use LINE during this semester. & .701 & & & \\
\hline $\begin{array}{l}\text { 2. I intend to use LINE in my coursework as } \\
\text { often as I possible. }\end{array}$ & .533 & & & \\
\hline 3. I plan to use LINE in the future. & .560 & & & \\
\hline \multicolumn{1}{|c|}{ Total \%t of variance } & & & 64.134 & \\
\hline
\end{tabular}

The cumulative percentage of explained variance was $64.134 \%$, which meant that all four factors could explain $64.134 \%$ of variation of perception of students. The factor scores were used as dependent variables in the test to see their relationships.

Research Question 3: Are there any relationships between intention to use LINE, attitude towards LINE usage, perceived ease of LINE use, perceived usefulness of LINE, and number of social networks students are using?

This study employed a structural equation modeling approach to develop a model that represents the relationships among the five factors in this study: perceived usefulness (PU), perceived ease of use (PEOU), attitude towards usage (ATU) and intention to use (ITU) and the number of social network sites (NSNU) that students were using. The structural model and hypotheses were tested by examining the path coefficients and their significance. The path coefficients are presented in Figure 2. Perceived usefulness demonstrated a significant influence on intention to use (path = 0.252). Attitude toward usage demonstrated a significant influence on intention to use (path $=$ 0.288). Perceived ease of use had a significant influence on perceived usefulness (path $=0.661$ ). However, the link between number of social networks and intention to use (path $=0.033$ ), perceived ease of use and attitude toward usage (path $=-0.073$ ), perceived usefulness and attitude (path $=-0.081$ ), was not significant at the 0.5 level. 


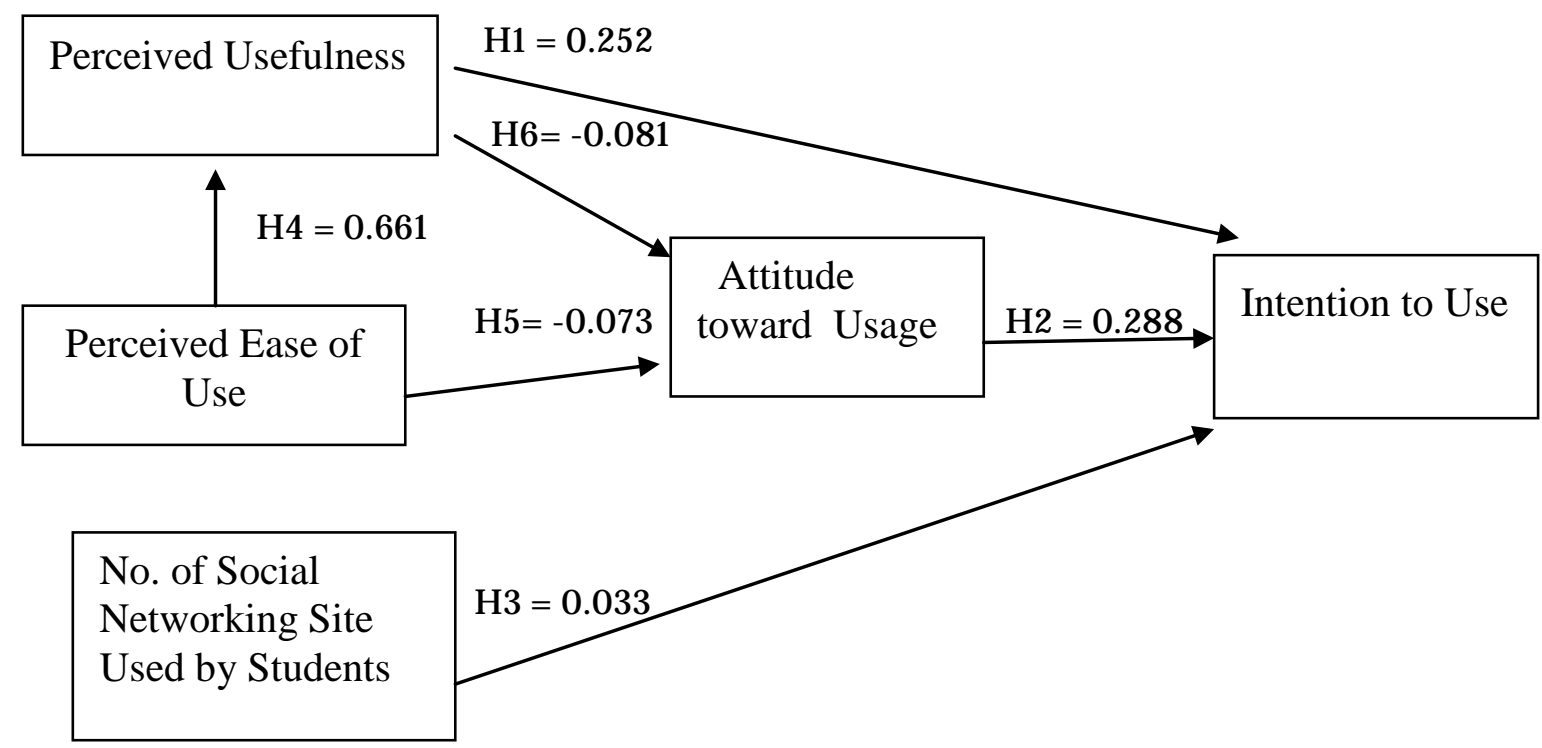

Figure 2. Path coefficient research model results.

The results indicated that three hypotheses were accepted while the other three hypotheses were rejected. That is, students' intention to use LINE for academic purposes was explained by the two significant factors. The first factor was perceived usefulness, $\beta=0.252, \mathrm{t}=3.106, \mathrm{p}=<01$ and the other was attitude toward usage, $\beta=0.288, \mathrm{t}=3.579, \mathrm{p}<01$. Therefore, $\mathrm{H} 1$ and $\mathrm{H} 2$ received support. In addition, perceived ease of use was found to be related to perceived usefulness, $\beta=$ 0.661, $\mathrm{t}=10.496, \mathrm{p}<01$, hence, $\mathrm{H} 4$ received support. The number of social network sites students were using was not related to intention to use and attitude toward usage with $P>0.05$, thus, H3 was rejected. Perceived ease of use was not found to have a relationship with attitude toward usage with $\mathrm{P}>0.05$, thus $\mathrm{H} 5$ was rejected. Hypothesis 6 proposed that perceived usefulness had a positive relationship with attitude toward usage, but the result did not find the relationship with $\mathrm{P}>.05$. Therefore, $\mathrm{H} 6$ was rejected. Table 3 summarizes the results obtained from testing the research hypotheses. 
Table 3

Results of Hypotheses Testing

\begin{tabular}{|l|l|l|l|l|}
\hline Hypotheses & Path & $\begin{array}{l}\text { Path } \\
\text { Coefficients }\end{array}$ & t-value & Results \\
\hline H1 & PU $\longrightarrow$ ITU & 0.252 & 3.106 & Supported, $\mathrm{P}<.01$ \\
\hline H2 & ATU $\longrightarrow$ ITU & 0.288 & 3.579 & Supported, $\mathrm{P}<.01$ \\
\hline H3 & NSNU $\longrightarrow$ ITU & 0.033 & 1.299 & Not supported, $\mathrm{P}>.05$ \\
\hline H4 & PEOU $\longrightarrow$ PU & 0.661 & 10.496 & Supported, $\mathrm{P}<.01$ \\
\hline H5 & PEOU $\longrightarrow$ ATU & -0.073 & -0.868 & Not supported, $\mathrm{P}>.05$ \\
\hline H6 & PU $\longrightarrow$ ATU & -0.081 & -0.965 & Not supported, $\mathrm{P}>.05$ \\
\hline
\end{tabular}

Research Question 4: What LINE-based activities do students prefer to have in future English courses?

Students were then asked to choose LINE-based activities that they would like to have in the future course. According to Table 4, students preferred to use LINE as a platform for communicating in English with their teacher (72.2\%), followed by reading the story posted by the teacher (56.9 \%), sharing opinions in English on the provided topic (42.4\%), and making a story using stickers in LINE (31.9 \%). Making a call through LINE to talk with the English teacher was the activity that students chose the least (14.6\%). Therefore, prospective activities which will be incorporated in future English courses are chatting in English and giving personal responses to prompts or questions after reading the story.

Table 4

Frequency and Percentage of LINE-based Language Learning

\begin{tabular}{llllc}
\hline \multicolumn{1}{c}{ Items } & \multicolumn{2}{c}{ Yes } & \multicolumn{3}{c}{ No } \\
\hline & Number & $\%$ & Number & \% \\
\hline $\begin{array}{l}\text { 1. communicate in English using LINE as a } \\
\text { platform }\end{array}$ & 104 & 72.2 & 40 & 27.8 \\
$\begin{array}{l}\text { 2. read the story posted by the teacher and } \\
\text { answer the questions or give a personal }\end{array}$ & 82 & 56.9 & 62 & 43.1 \\
$\quad \begin{array}{l}\text { response } \\
\text { 3. share opinions in English on the provided }\end{array}$ & 61 & 42.4 & 83 & 57.6 \\
$\quad \begin{array}{l}\text { topic } \\
\text { 4. make a story using stickers in LINE }\end{array}$ & 46 & 31.9 & 98 & 68.1 \\
$\quad$ make a call through LINE to talk with your & 21 & 14.6 & 123 & 85.4 \\
\hline
\end{tabular}




\section{Part II: Open-Ended Responses}

Research Question 5: What are the benefits and drawbacks of LINE usage for academic purposes?

The final section of the questionnaire asked the participants to respond to two open-ended questions. Firstly, they were asked to specify what they perceived as the main benefit of using LINE for academic purposes. After content analysis was conducted, it was found that the most cited reply was the convenience in connecting with their friends and the teacher in the course. It is fast to communicate with them. When they had any inquiries, they just typed and sent the message to the LINE group. They could get a reply even in a minute. They gained a lot of benefits from LINE where they could create a small group of close friends to consult with when a problem occurred. They could send questions to their teacher or communicate with friends when they had an assignment to do out-of-class. LINE helped them save time. The next benefit that students mentioned was saving money. They did not need to make a phone call. Talking on cell phones was changed to sending messages to LINE. The last advantage that two students stated was the ease of use when compared with LMS. They preferred to use LINE to contact the teacher if they could choose.

Secondly, they were asked to reveal what they considered as the main problem when LINE was used for academic purposes. Regarding the most significant drawback, the majority of students identified that sending video clips was not possible when they were too long. In this regard, they compared it with Facebook where they can upload longer video clips. Sending video clips in LINE was not convenient and still a problem. They would like the teacher to be aware of incorporating sound and video clips into text. The second most significant drawback students mentioned was when students did not have WiFi or $3 \mathrm{G}$ access on their mobile phones. This caused trouble since they were not able to update the content or news in LINE. Not being able to access to LINE made them miss important information. In addition, three students identified miscommunication or misinterpretation of the message which might occur. For them, face-to-face talking is more comprehending. Two students mentioned that sometimes the teacher did not have much time to reply or to explain about what they had asked. They would like to get the answers as soon as possible.

\section{Discussion}

The first issue which should be discussed is about perceived ease of use which is found to have an influence on perceived usefulness. We may conclude that comfort with LINE usage enables students to place more importance on usefulness. The more they are comfortable with LINE, the more they perceive its usefulness. One of the causes may have been from familiarity they have 
with LINE. Since it is the most popular application among the youth nowadays, a majority of students use it for social interaction. When LINE-based activities are incorporated into an English course, students seem to be more motivated to learn. Using LINE as a learning tool has led to acceptance for student/ teacher interaction. The LINE chat app immediately sets up the ability to exchange ideas without any hindrances that could be caused by gender, age and in the case of using LINE in an academic setting with a teacher. The factor of perceived ease of use highly influences the acceptance of LINE because it is a user-friendly tool. It allows users to make voice calls and send messages whenever and wherever they are, so it can be applied to create various classroom activities. The finding is found to be consistent with previous studies which employed TAM to investigate learners' adoption of electronic portfolio system (Shroff et al., 2011) and elearning system (Adwan et al., 2013). These studies revealed the positive relationship between perceived ease of use and perceived usefulness.

Another interesting finding is the relationships between perceived usefulness and intention to use, suggesting that the role of two factors in TAM has been conclusive. This is probably because students recognize that LINE can support their learning; they can improve their communication skills through messages and calls. LINE is deemed the most effective tool for communicating with the teacher and updating the information about the course. LINE offers the feature which can be used as learning management system. The use of LINE as a learning tool can successfully facilitate language learning. Students can do a lot of classroom activities using LINE app. Also, the responses to open-ended questions can support this positive finding in that students perceive LINE as an effective, cheap and fast tool when they have to communicate with their peers and teacher out-of-class. LINE makes learning more convenient since students can engage more in effective educational practices. Furthermore, using LINE for their coursework is like a direct experience, making them perceive it useful. This may be concluded that students accept the use of LINE for academic purposes because they recognize its benefits. This finding is in accordance with the previous studies using TAM in the contexts of e-learning (Liu et al., 2005) and mobile phone (Sek et al., 2010), proving that TAM is an effective model to explain the adoption of similar technologies.

One critical issue is the positive relationship between attitude toward usage and intention to use. According to Ajzen and Fishbein (2005), attitude is referred to the way that individuals respond to or ignore an object. A positive attitude that students have may come from fun when they join the LINE-based activities. The teacher is believed to be the most important factor making the learning environment more motivating. LINE is the only social networking site that provides relaxing activities the most. The generation gap which normally exists between students and teachers can be bridged by using stickers and emoticons attached to text messages when using LINE. When it is used for academic purposes, students still are able to send stickers to communicate their feelings regarding the study. When students have a positive attitude, they tend to use or accept LINE. This is probably because of the feature of LINE which can facilitate language learning effectively. Students learn that LINE is not only a social networking site used 
for personal purposes, but it is also excellent for language skill improvement. Their intention to use can be supported by the two highest rated activity shown in Table 4, indicating that students prefer chatting in English and giving personal responses to prompts or questions after reading the story. So, the learning process in the future course can be altered according to their needs. The result is found to be in line with TAM and supports the previous studies conducted on e-learning (Huang \& Liaw, 2005) and e-portfolio (Ng et al., 2013) in that attitude towards usage has a direct relationship to behavioral intention to use. Successful engagement in technologies requires users to possess a positive attitude towards it. However, the result is not consistent with a study by Teo \& van Schaik (2009), who found that attitude towards computer use did not have a significant influence on intention to use. Those studies have made the role of attitude in the TAM inconclusive. It is possible that users may use a technology even if they do not have a positive attitude towards the technology as long as it is perceived to be useful or easy to use (Davis et al., 1989).

It is surprising that perceived usefulness is not related to attitude towards usage in the present study. According to the data collected from the open-ended responses, students are still worried about sending video clips that seem to be difficult. Also they are afraid of miscommunication when they have to interact with the teacher through LINE. This implies that some students prefer face-to-face communication for the sake of study. In spite of these limitations, they still have positive attitude since there are many other things LINE can offer. A possible explanation for this result comes from Wee (2013) who states that what is unique about LINE is that the students are able to express themselves with more than just words or plain emoticons, but they also have a wide variety of characters to choose from that display different types of personalities. Also, they can easily create a small group of close friends to chat. These features encourage students to have a positive attitude no matter what they perceive about its usefulness. Consistent with prior research, perceived usefulness had no significant influence on students' attitude (Adwan et al., 2013). However, the finding is in contrast with what Park (2009b) and Chang et al. (2012) found in their studies that perceived usefulness had a great impact on attitude towards usage.

In contrast with the original assertions of TAM, the study did not find a significant relationship between students' perceived ease of use and attitude toward usage. This might be due to the fact that students nowadays are in the digital age. They can adopt new technologies better than the people in older generations. Learning how to use technologies is not a big deal, and they enjoy learning new things. Student acceptance to use LINE in the English course was, therefore, not related to what they perceive in terms of technology comfort. However, the finding is inconsistent with one study (Shroff et al., 2011) which found that perceive ease of use had a significant effect on attitude toward usage.

Another factor which does not have an influence on intention to use is the number of social network sites used by students. As found in the data collection, most students get involved with more than one social networking site. Using many kinds of social networks should have 
influenced intention to use, but in reality it did not. This is probably because students only use social networks for fun or for personal purposes. They spend a lot of time on matters that are not related to their study. On the contrary, the purpose of using social networks in the course is different. Using LINE for academic purposes is like a new method used to facilitate language learning. When students understand the objectives of using the new tool in the course and see the importance of using it, they tend to accept it. So, the issue of how much time they spend on social networking sites is not critical.

\section{Conclusion}

Based on the findings, TAM can be employed as a useful theoretical base to predict and understand students' intention to use LINE for academic purposes. The intention to use this technology in their learning can be motivated by presenting usefulness of technology. In this regard, the teacher is also required to recognize the potential of LINE for a productive student/ teacher interaction. A collaborative based learning methodology can be developed along with a multi-channel learning method using LINE in tandem with other digital media such as tablets and laptops. It is also important that students have a positive attitude and feel very comfortable with the ease of use with LINE. The responses that can be elicited by a teacher using LINE is also an area that needs to be looked at much more closely to determine if the interaction provided by LINE between a teacher and student actually reinforces a learning path for the student. Analyzing the conversation discourse using LINE, as demonstrated by Mazur (2004), can help a teacher to scaffold ideas within a student's social network thereby getting involved with relevant issues in their world thus equalizing the learning platform between teacher and student.

Apart from LINE which is a case presented in this study, TAM can also be used to examine a wider range of information system applications (Chen, $\mathrm{Li}, \& \mathrm{Li}, 2011)$. Testing TAM with the other disruptive technologies which allow instant communication anywhere and at any time is possible. In the context of education, not only is LINE included in this server side technology but also joins Facebook, Twitter, MySpace, Moodle, all of which facilitate communication and collaboration, extending the interactive experience of the classroom beyond the physical space and class period. On the one hand these social networks have disrupted traditional classroom teaching methodologies but have also introduced newer teaching possibilities allowing for innovative learning experiences. If there is a high level of acceptance by students to try new technologies to learn subject matter, the question is how the teachers will re-calibrate their approach to the students learning experience to accommodate their willingness to use these technological tools.

This work is licensed under a Creative Commons Attribution 4.0 International License. 


\section{References}

Adwan, A., Adwan, A., \& Smedley, J . (2013). Exploring students' acceptance of e-learning using technology acceptance model in J ordanian Universities. International J ournal of Education and Development using Information and Communication Technology, 9(2), 4-18.

Ajzen, I., \& Fishbein, M. (2005). The influence of attitudes on behavior. Retrieved February 5, 2014 from http:// web.psych.utoronto.ca/ psy320/Required\%20readings files/4-1.pdf

Brown, J . D. (1996). Testing in language programs. NJ : Prentice Hall Regents.

Chang, C., Yan, C., \&Tseng, J . (2012). Perceived convenience in an extended technology acceptance model: Mobile technology and English learning for college students. Australasian J ournal of Educational Technology, 28 (5), 809-826.

Chen, S., Li, S., \& Li, C. (2011). Recent related research in technology acceptance model: A literature review. Australian J ournal of Business and Management Research, 1(9),124-127.

Davis, F. D. (1989). Perceived usefulness, perceived ease of use, and user acceptance of information technology. MIS Quarterly, 13(3), 319-340.

Davis, F. D., Bagozzi, R. P., \&Warshaw, P. R. (1989). User acceptance of computer technology: A comparison of two theoretical models. Management Science, 35(8), 982- 1003.

Gabarre, S., \& Gabarre, C. (2013). Using mobile Facebook as an LMS: Exploring impeding factors. Gema Online J ournal of Language Studies, 13 (3), 99-115.

Gonzalez, D. (2003). Teaching and learning through chat: A taxonomy of educational chat for EFL/ ESL. Teaching English with technology, 3(4), 57-69.

Greenhow, C., \& Robelia, B. (2009). Informal learning and identity formation in online social networks. Learning, Media and Technology, 34, 119- 140.

Hair, W. C., Babin, B. J., Anderson, R. E., \&Tatham, R. L. (2006). Multiple data analysis. Upper Saddle River, NJ : Prentice Hall International.

Hsieh, S. W. (2011). Effects of cognitive styles on an MSN virtual learning companion system as an adjunct to classroom instructions. Educational Technology \& Society, 14(2), 161-174.

This work is licensed under a Creative Commons Attribution 4.0 International License. 
Hsu, J . (2007). Innovative technologies for education and learning: Education and knowledge-oriented applications of blogs, wikis, podcasts, and more. International J ournal of Information and Communication Technology Education, 3(3), 70-89.

Huang, M., \&Liaw, S. (2005). Exploring user's attitudes and intentions toward the web as survey tool. Computers in Human Behavior, 21 (5), pp.729-743.

Lee, J .-K., \& Lee, W.-K. (2008). The relationship of e-learner's self-regulatory efficacy and perception of e-learning environmental quality. Computers in Human Behavior, 24(1), 32-47. doi:10.1016/j.chb.2006.12.001

Lee, Y., Hsieh, Y., \& Hsu, C. (2011). Adding innovation diffusion theory to technology acceptance model: Supporting employees' intentions to use e-learning systems. Educational Technology \&Society, 14 (4), 124-137.

Liu, S., Liao, H., \&Peng, C. (2005). Applying the technology acceptance model and flow theory to online E-learning. Issues in Information Systems, 6(2), 175-181.

Mazur, J . M. (2004). Conversation analysis for educational technologists: Theoretical and methodological issues for researching the structures, processes and meaning of on-line talk. Handbook of research on educational communications and technology. $2^{\text {nd }}$ ed. pp.1073-1098. Mahwah, NJ : Lawrence Erlbaum.

McBrien, J ., J ones, P., \& Cheng, R. (2009). Virtual spaces: Employing a synchronous online classroom to facilitate student engagement in online learning. International Review of Research in Open and Distance Learning, 10(3), Retrieved December 12, 2013 from http:// www.irrodl.org/index.php/irrodl/article/view/605/1264

Ng, E., Shroff, R., \& Lim, C. (2013). Applying a modified technology acceptance model to qualitatively analyse the factors affecting e-portfolio implementation for student teachers' in field experience placements. Issues in Informing Science and Information Technology, 10, 355-365.

Nov, O., \&Ye, C. (2008). Users' personality and perceived ease of use of digital libraries: The case for resistance to change. J ournal of the American Society for Information Science and Technology, 59(5), 845-851.

Palloff, R. M., \& Pratt, K. (2007). Building online learning communities. San Francisco: J ossey-Bass. 
Park, N. (2009a). User acceptance of e-learning in higher education: An application of technology acceptance model. Paper presented at the Annual meeting of the International Communication Association, New York.

Park, S. (2009b). An analysis of the technology acceptance model in understanding university students' behavioural intention to use e-Learning. Education Technology \& Society, 12(3), 150-162.

Rovinelli, R. J ., \& Hambleton, R. K. (1977). On the use of content specialists in the assessment of criterion-referenced test item validity. Dutch J ournal of Educational Research, 2, 49-60.

Sek, Y., Lau, S., Teoh, K., \& Law, C. (2010). Prediction of user acceptance and adoption of smart phone for learning with technology acceptance model. J ournal of Applied Sciences, 10 (20), 2395-2402.

Shroff, R. H., Deneen, C. D., \&Ng, E. M. W. (2011). Analysis of the technology acceptance model in examining students' behavioural intention to use an eportfolio system. Australasian J ournal of Educational Technology, 27(4), 600618.

Stapa, S. H., \& Shaari, A.H. (2012). Understanding online communicative language features in social networking environment. Gema Online J ournal of Language Studies, 12(3), 817-830.

Teo, T. (2009). Modelling technology acceptance in education: A study of pre-service teachers. Computers \&Education, 52(2), 302-312. http:// dx.doi.org/ 10.1016/j.compedu.2008.08.006

Venkatesh, V., \& Davis, F. D. (2000a). A model of the antecedents of perceived ease of use: Development and test. Decision Sciences, 27(3), 451-481. doi:10.1111/j.15405915.1996.tb00860.x

Venkatesh, V., \& Davis, F. D. (2000b). A theoretical extension of the technology acceptance model: Four longitudinal field studies. Management Science, 46(2), 186-204.doi:10.1287/mnsc.46.2.186.11926

Wee, W. (2013). The growth story and future of mobile chat app giant LINE. Retrieved Feb 1, 2014, from http:// www.techinasia.com/ growth-story-future-mobile-chat giant- line/ 
Yi, M., \& Hwang, Y. (2003). Predicting the use of web-based information systems: Selfefficacy, enjoyment, learning goal orientation, and the technology acceptance model. International J ournal of Human-Computer Studies, 59, 431-449.

http://dx.doi.org/ 10.1016/S1071-5819 (03)00114-9

(C) Van De Bogart and Wichadee

\section{Athabasca University $\mathbf{A}$}

(c) (i) 